\title{
Management of two taurodont primary molars with pulp involvement using calcium-enriched mixture cement pulpotomy in a patient with accompanied drug reaction with eosinophilia and systemic symptoms syndrome: a case report
}

\author{
Sanaz Kamareh $^{1}$, Majid Kazem ${ }^{2}$, Maryam Foroozandeh ${ }^{3}$, Atefeh Gohari ${ }^{4, *(0)}$
}

${ }^{1}$ Postgraduate student at the Department of pediatric dentistry, Dental School, Shahid Beheshti University of Medical Sciences, Tehran, Iran

${ }^{2}$ Professor at the Department of endodontics, Dental School, Shahid Beheshti University of Medical Sciences, Tehran, Iran

${ }^{3}$ Postgraduate student at the Department of Oral and Maxillofacial Radiology, Dental School, Hamadan University of Medical Sciences, Hamadan, Iran

${ }^{4}$ Postgraduate student at the Department of endodontics, Dental School, Shahid Beheshti University of Medical Sciences, Tehran, Iran

\section{Correspondence}

Atefeh Gohari, Postgraduate student at the Department of endodontics, Dental School, Shahid Beheshti University of Medical Sciences, Tehran, Iran

Email: atp.gohari@gmail.com

History

- Received: Mar 20, 2019

- Accepted: May 16, 2019

- Published: May 31, 2019

DOI :

https://doi.org/10.15419/bmrat.v6i5.545

\section{Check for updates}

\section{Copyright}

( ) Biomedpress. This is an openaccess article distributed under the terms of the Creative Commons Attribution 4.0 International license.

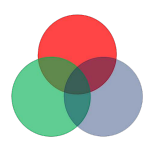

\begin{abstract}
Background: Taurodontism is considered a variation in tooth morphology associated with several syndromes. Case Presentation: This report presents a case of taurodontism associated with drug reaction with eosinophilia and systemic symptoms (DRESS) syndrome. A 5-year-old girl, with a history of DRESS syndrome, was referred to the department of pediatric dentistry at the School of Dentistry, Shahid Beheshti University of Medical Sciences, with a chief complaint of toothache. Clinical and Radiographic examinations showed deep carious lesions with large pulp chambers and short roots present in relation to second mandibular primary molars. Routine pulpectomy could not be performed as a result of complex tooth morphology. Instead, we played a deep pulpotomy with calcium-enriched mixture cement agent, and the crowns were restored. Follow-up observations after six and 12 months showed that the tooth was asymptomatic, clinical and radiographic examinations revealed no swelling, no sensitivity to percussion and palpation. Conclusion: In patients with carious taurodont deciduous teeth, deep pulpotomy with biomaterials such as calcium-enriched mixture cement can result in favorable outcomes.
\end{abstract}

Key words: Deciduous Teeth, DRESS syndrome, Taurodontism, Vital Pulp Therapy

\section{INTRODUCTION}

Taurodontism is considered a variation in tooth and root canal system morphology that usually occurs in molars and occasionally in premolars ${ }^{1}$. Witkop defined taurodontism as an anomaly in which large pulp chambers are present, and the bifurcation is located apically. Therefore, the pulp chamber has deeper apico-coronal height and the constriction, which is present generally at the level of cementoenamel junction (CEJ), is absent $)^{1}$. This anomaly is characterized by enlarged pulp chamber which is deeply extended into the roots. The complex anatomy makes endodontic treatments difficult ${ }^{2}$.

Theoretically, taurodontism might have several etiologic factors. It is proposed that the anomaly can occur due to a genetic mutation or result from a retrograde nature. It can be considered as an X-linked trait with familial or autosomal dominant characteristics ${ }^{3}$.

Although taurodontism most frequently appears as an isolated anomaly, it can be associated with several developmental syndromes and abnormalities such as amelogenesis imperfecta, ectodermal dysplasia, Down's syndrome, tricho-dento-osseous syndrome, Klinefelter syndrome, Mohr syndrome, WolfHirschhorn syndrome and Lowe syndrome ${ }^{4}$. The presence of taurodontism in association with other rare syndromes such as Smith-Magenis syndrome ${ }^{5}$, Williams syndrome ${ }^{6}$, Van der Woude syndrome ${ }^{7}$ and McCune-Albright syndrome ${ }^{8}$ has also been reported.

\section{CASE PRESENTATION}

A 5-year-old girl, with a history of DRESS syndrome, was referred to the department of pediatric dentistry at the School of Dentistry, Shahid Beheshti University of Medical Sciences, with a chief complaint of toothache. Clinical examination showed several carious lesions in primary molars with extreme sensitivity to cold and percussion on teeth 75 and 85 . Periapical abscesses were present on the buccal vestibule of the maxillary right and left first primary molars. Radiographic examination revealed deep carious lesions with large pulp chambers and short roots in relation to teeth 75 and 85 (Figure 1a,b). A panoramic view radiograph was ordered to evaluate other primary
Cite this article : Kamareh S, Kazem M, Foroozandeh M, Gohari A. Management of two taurodont primary molars with pulp involvement using calcium-enriched mixture cement pulpotomy in a patient with accompanied drug reaction with eosinophilia and systemic symptoms syndrome: a case report. Biomed. Res. Ther.; 6(5):3184-8188. 
teeth and to assess the development of un-erupted permanent teeth. The panoramic view showed that all primary molars had large pulp chambers and short roots, suggesting taurodontism. Additionally, the left mandibular second premolar bud was absent (Figure 2).

Based on the subjective, objective, and radiographic findings, as the patient, was diagnosed with taurodontism for teeth 75 and 85 . Tooth 75 and 85 noted as having irreversible pulpitis/symptomatic apical periodontitis. Taurodontism could not be diagnosed in permanent first premolars and molars due to early developmental stages, but these teeth also showed some signs of taurodontism.

The patient's parents were suggested a treatment plan and a. written informed consent was obtained. Mandibular second primary molars were treated in two separate appointments. Access cavities were prepared, and the remaining pulp tissues were extirpated under local anesthesia, through inferior alveolar nerve block of 3\% Plain Mepivacaine (Exir Pharmaceutical Co., Boroojerd, Iran) and latex-free rubber dam isolation. The pulp chamber was deep, and the floor of the chamber could not be visualized. To ensure complete removal of the tissue and biofilm, 2.5\% sodium hypochlorite (Golrang Co., Pakshou, Tehran, Iran) and normal saline were used alternatively as irrigation agents.

Both teeth were extremely hyperemic. However, routine pulpectomy could not be quickly done due to abnormal tooth morphology. On the other hand, mandibular first permanent molars had not erupted yet, so maintaining the second primary molars was important. Consequently, deep pulpotomy was performed on both teeth, using a calcium-enriched mixture cement agent (CEM cement). After that, the teeth were restored with stainless steel crowns. First primary maxillary molars were extracted because of root resorption and abscess, and two band and loops were used for space maintenance.

After six months, both mandibular second primary molars were asymptomatic and clinical examination revealed no swelling, no sensitivity to percussion or palpation. Besides, radiographic examinations showed no pathological changes (Figure 3a,b).

\section{DISCUSSION}

Drug reaction with eosinophilia and systemic symptoms (DRESS) syndrome, also known as drug-induced hypersensitivity syndrome (DIHS), is an under-recognized and potentially life-threatening hypersensitivity reaction associated with a variety of medications ${ }^{9}$. Patients with DRESS syndrome typically present rash, swelling, fever, and systemic manifestations such as a severe transaminitis ${ }^{9}$. In severe cases, the face, trunk, and upper extremities are affected by initial morbilliform rash. The rash gradually transitions into maculopapular and finally can progress to edema of the face, particularly in the periorbital region ${ }^{10}$. In the present case, the disease was entirely under control according to her physician's consultation, and the patient had no skin rash.

Although rash and eosinophilia are common in hypersensitivity reactions, the defining and differentiating characteristic of DRESS syndrome is organ dysfunction, primarily related to liver, kidneys, heart, or lungs. Patients are typically found to have taken a few medications in the past two to eight weeks, with aromatic anti-epileptics being the most common causative factor ${ }^{11-14}$. Traditionally, non-aromatic anti-epileptic medications such as topiramate, ethosuximide, and levetiracetam were thought to be safer; however, a recent case report describes DRESS syndrome in a patient taking only levetiracetam ${ }^{15}$. None of the drugs, administered by that patient (such as anesthetic agents and analgesics) were contraindicated for patients with DRESS syndrome. We used latex-free gloves and rubber dam to ensure extreme caution. Epinephrine-containing anesthetic solutions were not used because of a possible allergic reaction to sulfite, which is used as a component to prevent oxidation in vasoconstrictor agents ${ }^{16}$.

The simultaneous occurrence of DRESS syndrome and taurodontism, in this case, is probably accidental; however, since taurodontism is seen in association with several syndromes, it can represent some degree of association with DRESS syndrome.

Some authors claim that taurodontism can be associated with hypodontia. Others did not support the hypothesis that isolated tooth agenesis can be associated with taurodontism ${ }^{17}$. In the current case, taurodontism co-existed with agenesis of the left mandibular second premolar.

Taurodontism clinically appears as a healthy tooth with no apparent anomaly in the clinical crown. Therefore, the diagnosis of taurodontism is usually a subjective determination made from diagnostic radiographs ${ }^{18}$.

Performing non-surgical root canal treatment for taurodont teeth, especially in permanent teeth, 


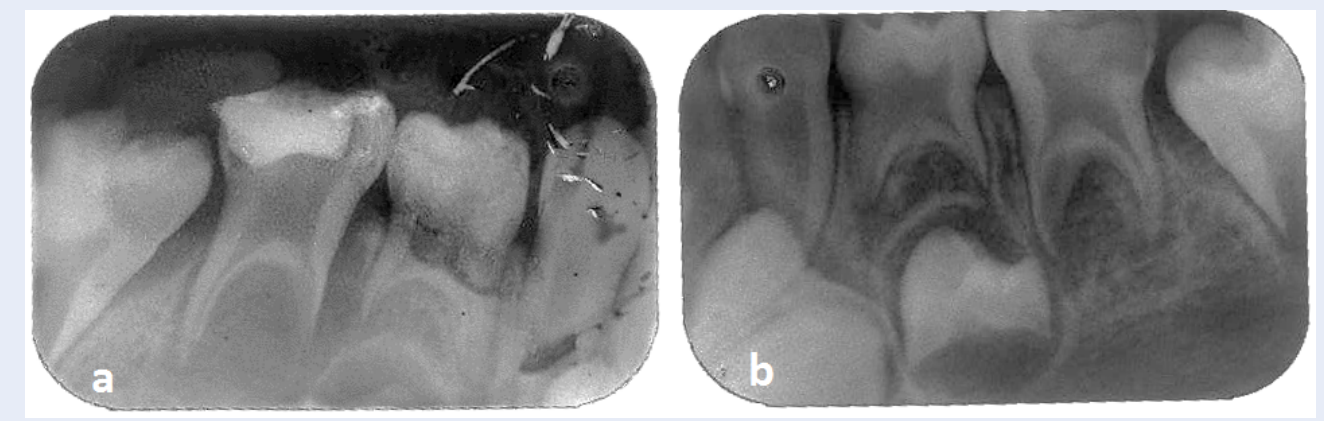

Figure 1: Radiographic examination revealed deep carious lesions with large pulp chambers and short roots in relation to teeth 75 and 85 , suggesting taurodontism.

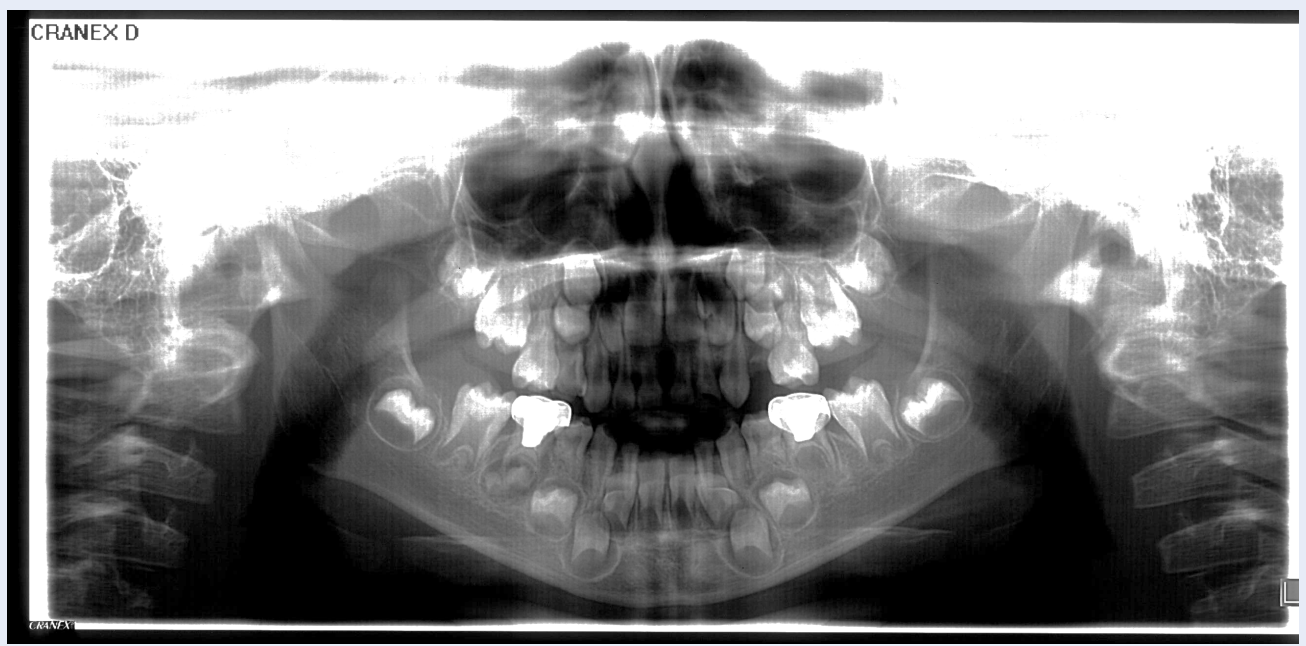

Figure 2: Panoramic view revealed that all primary molars have big pulp chambers and short roots and the absence of left mandibular second premolar bud.

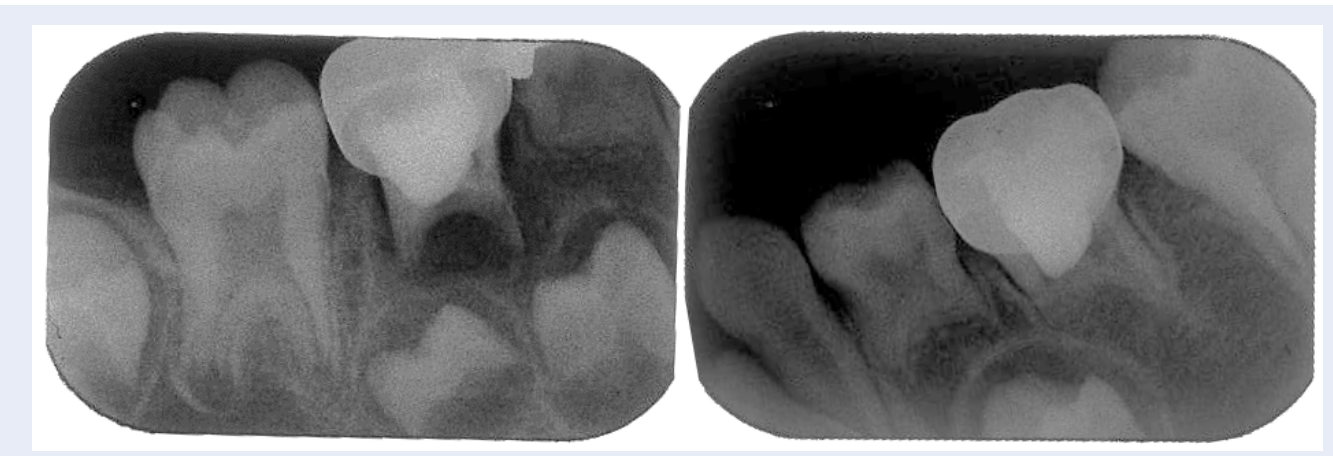

Figure 3: On 6-months follow up, radiographs showed nopathologic changes. 
may be difficult and the clinician may encounter several problems because of deep and large pulp chambers which complicate finding canal orifices. Besides, increased and profound bleeding during access opening may be misdiagnosed as furcation perforation ${ }^{19}$. The large and irregular volume of the pulp chamber makes adequate cleaning and shaping difficult. Therefore, irrigation by means of sodium hypochlorite has been suggested as an optimal method of disinfection. Using Passive Ultrasonic Irrigation (PUI) is also suggested for proper cleaning of irregular root canal systems ${ }^{20}$. However, controlling the cutting of dentin during ultrasonic use is either difficult or impossible ${ }^{21}$. Deciduous teeth anatomically have thinner dentin in comparison with permanent teeth ${ }^{2}$. Therefore, for those teeth, we did not use ultrasonic irrigation but performed copious irrigation with $2.5 \%$ sodium hypochlorite instead. Full strength sodium hypochlorite (5.25\%) was also avoided due to a potential allergic reaction to the chlorine component of sodium hypochlorite. Additionally, the whole procedure was performed under full isolation of a rubber dam to prevent any leakage.

Biomaterials such as mineral trioxide aggregate (MTA) and CEM showed favorable treatment outcomes for full pulpotomy of carious primary molars; CEM could be an effective and inexpensive pulp dressing biomaterial ${ }^{22}$.

Zinc oxide eugenol has been the material of choice for primary teeth pulp therapy for a long time ${ }^{2}$. Zinc eugenolate is highly unstable and undergoes hydrolysis. Therefore, releasing eugenol can induce type IV hypersensitivity or even generalized anaphylactic reactions ${ }^{23,24}$. Hence, since this case had a history of multiple drug reactions, we used CEM cement as a pulpotomy agent instead of traditional formocresol/zinc oxide eugenol. Patients with taurodont teeth require regular follow-up examinations to precisely monitor, prevent, and treat carious lesions in permanent teeth before pulp are involved.

\section{CONCLUSION}

Although taurodontism is a rare anomaly, it requires precise attention during clinical and radiographic examination for diagnosis and treatment planning. The clinician should be aware of complexities in the canal system as well as other associated syndromes. This report reveals that in patients suffering from symptomatic taurodont deciduous teeth, deep pulpotomy with biomaterials such as CEM cement can result in favorable outcomes.

\section{CONSENT}

Written informed consent was obtained from the patient for publication of this Case Report and any accompanying images. A copy of the written consent is available for review by the Editor-in-Chief of this journal

\section{COMPETING INTERESTS}

Authors deny any conflict of interests.

\section{AUTHORS' CONTRIBUTIONS}

Sanaz Kamareh participated in treating the patient, acquisition of data and drafting of the manuscript. Majid Kazem participated in acquisition and interpretation of data and drafting of the manuscript. Maryam Foroozandeh and Atefeh Gohari both participated in drafting of the manuscript and interpretation of data. All authors read and approved the final manuscript.

\section{REFERENCES}

1. Witkop CJ. Manifestations of genetic diseases in the human pulp. Oral Surg Oral Med Oral Pathol. 1971;32(2):278-316. 4327157. Available from: 10.1016/0030-4220(71)90232-5.

2. McDonald R, Avery D, Dean J. Dentistry for the child and adolescent. Oxford: Mosby; 2016.

3. Bhat SS, Sargod S, Mohammed SV. Taurodontism in deciduous Molars - A Case Report. J Indian Soc Pedod Prev Dent. 2004;22(4):193-6. 15855716.

4. Joseph M. Endodontic treatment in three taurodontic teeth associated with 48,XXXY Klinefelter syndrome: a review and case report. Oral Surg Oral Med Oral Pathol Oral Radiol Endod. 2008;105(5):670-7. 18442747. Available from: 10.1016/j. tripleo.2007.11.015.

5. Tomona N, Smith AC, Guadagnini JP, Hart TC. Craniofacial and dental phenotype of Smith-Magenis syndrome. Am J Med Genet A. 2006;140(23):2556-61. 17001665. Available from: 10.1002/ajmg.a.31371.

6. Axelsson S, Bjørnland T, Kjaer I, Heiberg A, Storhaug K. Dental characteristics in Williams syndrome: a clinical and radiographic evaluation. Acta Odontol Scand. 2003;61(3):129-36. 12868685. Available from: 10.1080/00016350310001451.

7. Nawa H, Oberoi S, Vargervik K. Taurodontism and Van der Woude syndrome. Is there an association? Angle Orthod. 2008;78(5):832-7. 18298211. Available from: 10.2319/081707384.1 .

8. Akintoye SO, Lee JS, Feimster T, Booher S, Brahim J, Kingman A, et al. Dental characteristics of fibrous dysplasia and McCune-Albright syndrome. Oral Surg Oral Med Oral Pathol Oral Radiol Endod. 2003;96(3):275-82. 12973283. Available from: 10.1016/S1079-2104(03)00225-7.

9. Bocquet H, Bagot M, Roujeau JC. Drug-induced pseudolymphoma and drug hypersensitivity syndrome (Drug Rash with Eosinophilia and Systemic Symptoms: DRESS). Semin Cutan Med Surg. 1996;15(4):250-7. 9069593. Available from: 10.1016/S1085-5629(96)80038-1.

10. Shiohara $T$, lijima M, Ikezawa $Z$, Hashimoto $K$. The diagnosis of a DRESS syndrome has been sufficiently established on the basis of typical clinical features and viral reactivations. $\mathrm{Br} \mathrm{J}$ Dermatol. 2007;156(5):1083-4. 17381452. Available from: 10. 1111/j.1365-2133.2007.07807.x.

11. Vauthey L, Uçkay I, Abrassart S, Bernard L, Assal M, Ferry $T$, et al. Vancomycin-induced DRESS syndrome in a female patient. Pharmacology. 2008;82(2):138-41. 18607115. Available from: $10.1159 / 000142729$. 
12. Savard S, Desmeules S, Riopel J, Agharazii M. Linezolidassociated acute interstitial nephritis and drug rash with eosinophilia and systemic symptoms (DRESS) syndrome. Am J Kidney Dis. 2009;54(6):e17-20. 19733945. Available from: 10.1053/j.ajkd.2009.07.013.

13. Velema MS, Voerman HJ. DRESS syndrome caused by nitrofurantoin. Neth J Med. 2009;67(4):147-9. 19581659.

14. Criado PR, Criado RF, Avancini JM, Santi CG. Drug reaction with Eosinophilia and Systemic Symptoms (DRESS) / Drug-induced Hypersensitivity Syndrome (DIHS): a review of current concepts. An Bras Dermatol. 2012;87(3):435-49. 22714760. Available from: 10.1590/S0365-05962012000300013.

15. Gómez-Zorrilla $S$, Ferraz AV, Pedrós $C$, Lemus $M$, Peña C. Levetiracetam-induced drug reaction with eosinophilia and systemic symptoms syndrome. Ann Pharmacother. 2012;46(7-8):e20. 22764327. Available from: 10.1345/aph. 1 R084.

16. New sulfite regulations. FDA Drug Bull. 1986;16:17-8. 3817345.

17. Küchler EC, Risso PDA, Costa MDC, Modesto A, Vieira AR. Assessing the proposed association between tooth agenesis and taurodontism in 975 paediatric subjects. Int J Paediatr Dent. 2008;18(3):231-4. 18384350. Available from: 10.1111/j. 1365-263X.2007.00876.x.

18. Jafarzadeh H, Azarpazhooh A, Mayhall JT. Taurodontism: a review of the condition and endodontic treatment challenges.
Int Endod J. 2008;41(5):375-88. 18363703. Available from: 10.1111/j.1365-2591.2008.01388.x.

19. Rao A, Arathi R. Taurodontism of deciduous and permanent molars: report of two cases. J Indian Soc Pedod Prev Dent. 2006;24(1):42-4. 16582531. Available from: 10.4103/09704388.22836 .

20. Simsek N, Keles A, Ocak MS. Endodontic treatment of hypertaurodontism with multiple bilateral taurodontism. J Conserv Dent. 2013;16(5):477-9. 24082583. Available from: 10.4103/ 0972-0707.117497.

21. Lumley PJ, Walmsley AD, Walton RE, Rippin JW. Effect of precurving endosonic files on the amount of debris and smear layer remaining in curved root canals. J Endod. 1992;18(12):616-9. 1298802. Available from: 10.1016/S00992399(06)81333-6.

22. Malekafzali B, Shekarchi F, Asgary S. Treatment outcomes of pulpotomy in primary molars using two endodontic biomaterials. A 2-year randomised clinical trial. European journal of paediatric dentistry : official journal of European Academy of Paediatric Dentistry. 2011;12(3):189-93. 22077689.

23. Karabucak B, Stoopler ET. Root canal treatment on a patient with zinc oxide allergy: a case report. Int Endod J. 2007;40(10):800-7. 17608675. Available from: 10.1111/j.13652591.2007.01275.x.

24. Grade AC, Martens BP. Chronic urticaria due to dental eugenol. Dermatologica. 1989;178(4):217-20. 2767290. Available from: $10.1159 / 000248431$. 